\title{
Biochar improves the fertility of a Mediterranean vineyard without toxic impact on the microbial community
}

\author{
Anita Maienza ${ }^{1}$ - Silvia Baronti ${ }^{1}$ - Alessandra Cincinelli ${ }^{2}$. Tania Martellini $^{2}$ • \\ Antonio Grisolia $^{2}$ - Franco Miglietta ${ }^{1,3}$ - Giancarlo Renella ${ }^{4}$ - Silvia Rita Stazi ${ }^{5}$. \\ Francesco Primo Vaccari $^{1} \cdot$ Lorenzo Genesio $^{1}$
}

Accepted: 11 September 2017 / Published online: 2 October 2017

(C) INRA and Springer-Verlag France SAS 2017

\begin{abstract}
Incorporation of biochar into agricultural soils has been repeatedly proposed as an effective strategy to mitigate climate change with beneficial effects on soil properties and crop production. Results from previous field experiments showed that, when applied to vineyards, biochar amendment increased yield without a negative impact on grape quality, decreasing water stress during droughts and improving soil physical and chemical properties. Despite those positive impacts, the long-term effects of biochar treatment on soil fertility and ecological toxicity have seldom been studied at a real farm scale. We investigated the effects of biochar amendment on vineyard soil subjected to a single and a repeated biochar application focusing on total heavy metal concentration and availability, concentration and persistence of polycyclic aromatic hydrocarbons (PAHs), soil toxicity, and soil microbial community structure over a 5-year period. Our results showed that a longer term biochar application in a vineyard has no impact on soil microorganisms and does not retain toxic
\end{abstract}

Anita Maienza

a.maienza@ibimet.cnr.it

1 Institute of Biometeorology, National Research Council (IBIMET-CNR), Via G. Caproni 8, 50145 Florence, Italy

2 Department of Chemistry "Ugo Schiff”, University of Florence, Via della Lastruccia 3, Sesto Fiorentino, 50019 Florence, Italy

3 IMéRA, Institut de Recherches Avancees, Université Aix-Marseille, 2, Place Le Verrier, 13004 Marseille, France

4 Department of Agrifood Production Science and Environment Sciences (DISPAA), University of Florence, P.le delle Cascine 28, 50144 Florence, Italy

5 Department for Innovation in Biological, Agri-Food and Forest Systems (DIBAF), University of Tuscia, Via S. Camillo de Lellis s.n.c, 01100 Viterbo, Italy compounds (PAH and heavy metals). For the first time in biochar research, we investigate the biochar effect on a perennial crop and correlate the PAH retention with soil microbiota. Our research demonstrates that biochar application in a Mediterranean vineyard does not have a negative impact on soil ecology, reinforcing the perception that biochar is a sustainable option at farm scale, meeting the needs of agronomy and climate change mitigation.

Keywords Biochar $\cdot$ Vineyard $\cdot$ Heavy metals $\cdot$ PAHs · Eco-toxicity $\cdot$ Microbial community structure

\section{Introduction}

The use of biochar in agriculture is a carbon sequestration strategy with well-documented beneficial effects on soil and crops, driving an overall increase in soil ecosystem services (Schmidt et al. 2014). Despite these positive impacts, the longterm effects of biochar treatment have seldom been studied at a real farm scale.

The incorporation of biochar into agricultural soil may alter the main physico-chemical properties by inducing alkalization, and base cation content and its liming effect can increase nutrient availability in acidic soils (Lehmann and Joseph 2009).

Additional biochar-induced positive effects are the enhancement of water retention (Baronti et al. 2014), reduction of toxin-induced stress to microorganisms and plants, and chemisorption of soil pollutants (Liao et al. 2016). Nevertheless, further unintended changes in soil properties that may follow biochar application are of concern when considering soil function and its ecosystem services as part of the energy/matter links in the soil food chain (Castracani et al. 2015). 
The main biochar-borne pollutants that could cause a harmful long-term environmental impact are polycyclic aromatic hydrocarbons (PAHs), which are known to be genotoxic (Rombolà et al. 2015). The influence of feedstock and pyrolysis temperature on PAH concentrations in biochar, as well as correlation of PAH levels with biochar toxicity, had previously been investigated in the laboratory (Stefaniuk et al. 2016).

Currently, there are only a few field trials in Europe where perennial crops are grown on biochar-amended soils, and only two concerning vineyards (Baronti et al. 2014; Schmidt et al. 2014). While these field experiments have shown an increase in grape yield (Genesio et al. 2015), mainly attributed to improved soil water retention (Baronti et al. 2014) and soil ecological services (Mackie et al. 2015), there is still insufficient information on the persistence of PAHs in biochar-amended soils and on their potential toxic impact.

Soil microorganisms play a fundamental role in soil fertility by decomposing organic matter, mineralizing nutrients into plant available forms, and establishing positive relations with plants. However, soil microbial communities are sensitive to changes in soil properties and their responses can be in terms of both total biomass and composition (Nannipieri et al. 2012). Soil amended with organic and inorganic materials generally alter the typical composition of soil communities, with either positive or negative effects, which are transient or permanent depending on the characteristics of the incorporated amendment. Among the methods for characterizing microbial communities, the analysis of ester-linked fatty acid methyl ester (EL-FAME) profiles provides useful information on the abundance of specific microbial groups within the soil communities, such as bacteria, fungi, actinomycetes, and Gram-negative and Gram-positive bacteria (Zelles, 1999). The effects of biochar amendment on soil microbiome are still controversial, as some previous studies have shown that biochar may alter the soil microbial community structure (Jenkins et al. 2016), whereas others have reported limited impacts (Imparato et al. 2016). However, due to the scarcity of field experiments on biochar incorporation, its potential eco-toxicological impact is still poorly known.

In this work, we studied the effects of biochar application to vineyard soil, in a Mediterranean environment, subjected to single and repeated biochar amendments (B and BB) (Fig. 1). We report the concentration of PAHs and heavy metals, soil toxicity, and effect of the biochar amendment on the main soil properties and microbial community structure over a 5-year period. The study provides fundamental information, showing the impact of biochar amendment on soil microbial groups involved in key agroecological processes, on the duration of changes in soil properties, and on the persistence of organic and inorganic biochar-derived pollutants in soil in a farm-scale trial.

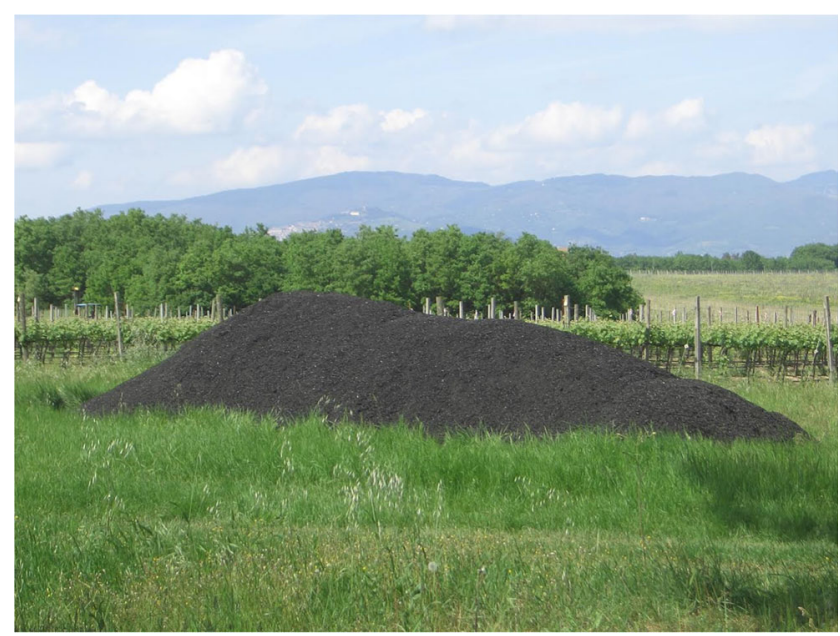

Fig. 1 Biochar application in the Mediterranean vineyard

\section{Materials and methods}

\subsection{Field trial and determination of soil and biochar chemical properties}

This study is part of a larger field experiment on the effects of biochar on vine crop stands. Briefly, the experiment was set up in 2009 in a vineyard on the Marchesi Antinori-La Braccesca Estate (lat. $43^{\circ} 10^{\prime} 15^{\prime \prime} \mathrm{N}$; long. $11^{\circ} 57^{\prime} 43^{\prime \prime} \mathrm{E} ; 290 \mathrm{~m}$ above sea level), located in the Montepulciano area (Tuscany, Central Italy). Biochar was applied on the inter-row of the vineyard in 2009 at a rate of $30 \mathrm{tha}^{-1}$ (B treatment); a further application at the same rate was made on some of the plots in 2010 (BB treatment). The experimental layout is therefore composed of two biochar treatments (B and $\mathrm{BB}$ ) and a control (C) in five replicates (15 plots in total with a surface of $225 \mathrm{~m}^{2}$ ). Details on agronomic management, soil and biochar properties, are reported by Baronti et al. (2014) and Genesio et al. (2015).

The biochar available metals were determined by extraction with $\mathrm{MgCl}_{2}$ and analyzed by OE-ICP (Iris Intrepid II XSP, Thermo Electron Corporation, NYSE:TMO).

Soil samples were taken in spring (April-May) 2010, 2011, 2012, 2013, and 2014 with a soil core sampler at a depth of 0 $30 \mathrm{~cm}$. For chemical analyses, soil samples were air-dried and sieved at $2 \mathrm{~mm}$. The soil $\mathrm{pH}$ value was measured in water solution (1:2.5 ratio); total organic $\mathrm{C}$ and total $\mathrm{N}$ were determined with a dry combustion elemental analyzer (Thermo Fisher Scientific Inc., USA). Concentrations of exchangeable base cations $(\mathrm{K}, \mathrm{Na}, \mathrm{Mg}$, and $\mathrm{Ca}$ ) were quantified by extraction with $\mathrm{BaCl}_{2}$-triethanolamine by OE-ICP. Available $\mathrm{P}\left(\mathrm{P}_{\mathrm{av}}\right)$ was determined according to the Olsen method (Olsen and Sommers, 1982). Total heavy metal concentrations were determined by microwave-assisted acid digestion (MARS, CEM) using concentrated $\mathrm{HNO}_{3}$ followed by metal quantification by OE-ICP. Heavy metal bio-available fraction was 
quantified by soil extraction with EDTA solution (Lakanen and Erviö 1971).

\subsection{Determination of soil PAH concentrations and soil toxicity}

For the 16 US EPA priority PAH analyses, $2.5 \mathrm{~g}$ of soil samples were homogenized, freeze-dried (Lio-5P, 5Pascal), and ultrasonically extracted three times with a mixture of $1: 1$ acetone/hexane (Fluka), followed by vortex swirl and centrifugation (Mattei et al. 2016). Prior to extraction, all samples and blanks were spiked with a surrogate standard solution (fluoranthene $\mathrm{d}_{10}$, benzo(a)pyrene $\mathrm{d}_{12}$, and p-terpenyl $\mathrm{d}_{4}$; Sigma-Aldrich) to monitor the analytical recovery efficiencies. The three extracts were combined and reduced in volume under a gentle nitrogen stream until a volume of $2 \mathrm{ml}$. The extracts were then cleaned up on silica gel columns (100/200 mesh; Sigma-Aldrich), blown down using a rotary evaporator (BUCHI, Germany) and high-purity nitrogen stream, and spiked with an internal standard mixture (naphthalene- $\mathrm{d}_{8}$, phenanthrene- $\mathrm{d}_{10}$, chrysene- $\mathrm{d}_{12}$, and indenopyrene- $\mathrm{d}_{12}$ ) before gas chromatography-mass spectrometry (GC-MS) analysis. PAHs were identified and quantified using an Agilent $6890 \mathrm{~N}$ gas chromatograph (GC) equipped with a mass selective detector (Agilent 5973 inert MSD). The capillary column was a DB-35 ms column $(30 \mathrm{~m} \times 0.25 \mathrm{~mm} \times 0.25 \mu \mathrm{m}, \mathrm{J} \& \mathrm{~W}$ Scientific, Folsom, CA, USA). The GC temperature program was $50^{\circ} \mathrm{C}$ for $1 \mathrm{~min}$, ramped at $25^{\circ} \mathrm{C} \mathrm{min}^{-1}$ to $125^{\circ} \mathrm{C}$, then at $8^{\circ} \mathrm{C} \mathrm{min}^{-1}$ to $260^{\circ} \mathrm{C}$, and, finally, $5^{\circ} \mathrm{C} \mathrm{min}^{-1}$ to $300^{\circ} \mathrm{C}$, then held for $14 \mathrm{~min}$. The carrier gas was He (flow $1 \mathrm{ml} \mathrm{min}^{-1}$ ). All PAHs were analyzed in selected ion monitoring (SIM) mode. Compound identification was based on their retention times, target and qualifier ions of pure PAH standards, and on the MSD database (NIST, 98).

Soil toxicity was assayed using the BioTox ${ }^{\mathrm{TM}}$ Flash Test (Aboatox Oy, Turku, Finland), according to the standard method (ISO 21338) based on the inhibition of the luciferase activity of the bioluminescent Vibrio fischeri. For this test, soil is considered toxic for bioluminescence when inhibition $>20 \%$ (Lappalainen et al. 2001).

\subsection{Microbial community structure}

Soil microbial community structure was analyzed by the ELFAME profiles, using $1 \mathrm{~g}$ of soil, and following the analytic extraction described by Schutter and Dick (2000). Fatty acids were separated by GC-MS. Methylated fatty acids were identified using BAME 24 and 37-Component FAME Mix as chemical standards (47080-U and 47885-U, respectively, Sigma-Aldrich, Milan, Italy). The identified EL-FAMEs were expressed as nanomoles of lipid per gram of soil, and additions of known amounts of nonadecanoic acid methyl ester (C19:0) were used as internal standard. The single acids were used as biomarkers of total microbial biomass, Gram+ and Gram- bacteria, fungi, and actinomycetes (Mummey et al. 2002).

Statistical analysis was performed using one-way analysis of variance (ANOVA), differences between treatments were detected by HSD Tukey test, and multivariate analysis by the statistical program JMP software from SAS Institute Inc.

\section{Results and discussion}

\subsection{Main soil properties}

Biochar (B and BB) applications significantly increased soil $\mathrm{pH}(p<0.001)$ and $\mathrm{C} / \mathrm{N}$ ratio compared to the control $(p<0.001)$ (Table 1a). No significant changes were observed for exchangeable $\mathrm{Na}, \mathrm{Mg}$, and $\mathrm{K}$ concentrations, while available phosphorus $\left(\mathrm{P}_{\mathrm{av}}\right)$ and $\mathrm{Ca}$ were increased in $\mathrm{B}$ and $\mathrm{BB}$ treatments (Fig. 2). Incorporation of biochar steadily neutralized the soil $\mathrm{pH}$ value, and increased $\mathrm{Mg}$ and $\mathrm{P}$ availability in B- and BB-amended soils and Ca in BB-amended soil. These results are in line with those of previous reports (Yang et al., 2015), confirming the rate-dependent modifications of $\mathrm{pH}$. Increases in exchangeable $\mathrm{Ca}$ and available $\mathrm{P}$ reflect the high base cations and $\mathrm{P}$ concentration of the biochar.

\subsection{Soil pollution and toxicity}

Total concentrations of heavy metals showed a significant increase of total $\mathrm{Pb}(p<0.001)$ in both $\mathrm{B}$ and $\mathrm{BB}$ treatments compared to those in the control soil, whereas total $\mathrm{Cu}$ concentration increased only slightly in the BB treatment as compared to that in the control and B treatment (Table 1a). Total concentrations of the other analyzed metals were not significantly different between treatments (Table 1a). Metal availability was not significantly increased by biochar treatments over time, except for a significant increase $(p<0.05)$ in available $\mathrm{Al}$ and Ni for BB in 2014 (Table 1b).

$\mathrm{Pb}$ and $\mathrm{Cu}$ concentrations were also increased in treated soils, but none of the metals exceeded current EU limits for agricultural soils (CEC 1986 n. 86/278/CEE). Moreover, the increase in total metal concentration is not related to an increase in their availability, confirming the capacity of biochar ash to stabilize heavy metals in soil (Mackie et al. 2015). The increase in $\mathrm{Al}$ and $\mathrm{Ni}$ availability observed in BB treatment in 2013 could be due to element mobilization caused by transient modifications of soil $\mathrm{pH}$ value and SOM solubility (Almaroai et al., 2014) due to prolonged heavy rainfall recorded in the area in 2013 (meteorological data shown in Genesio et al. 2015).

Biochar application led to an increase in the level of PAHs in soils compared to the control. Total PAH concentrations showed a decrease from 2013 to 2014 in both B and BB samples, varying from $101.7 \pm 15.5$ to $60.9 \pm 13.8 \mathrm{ng} \mathrm{g}^{-1}$ 


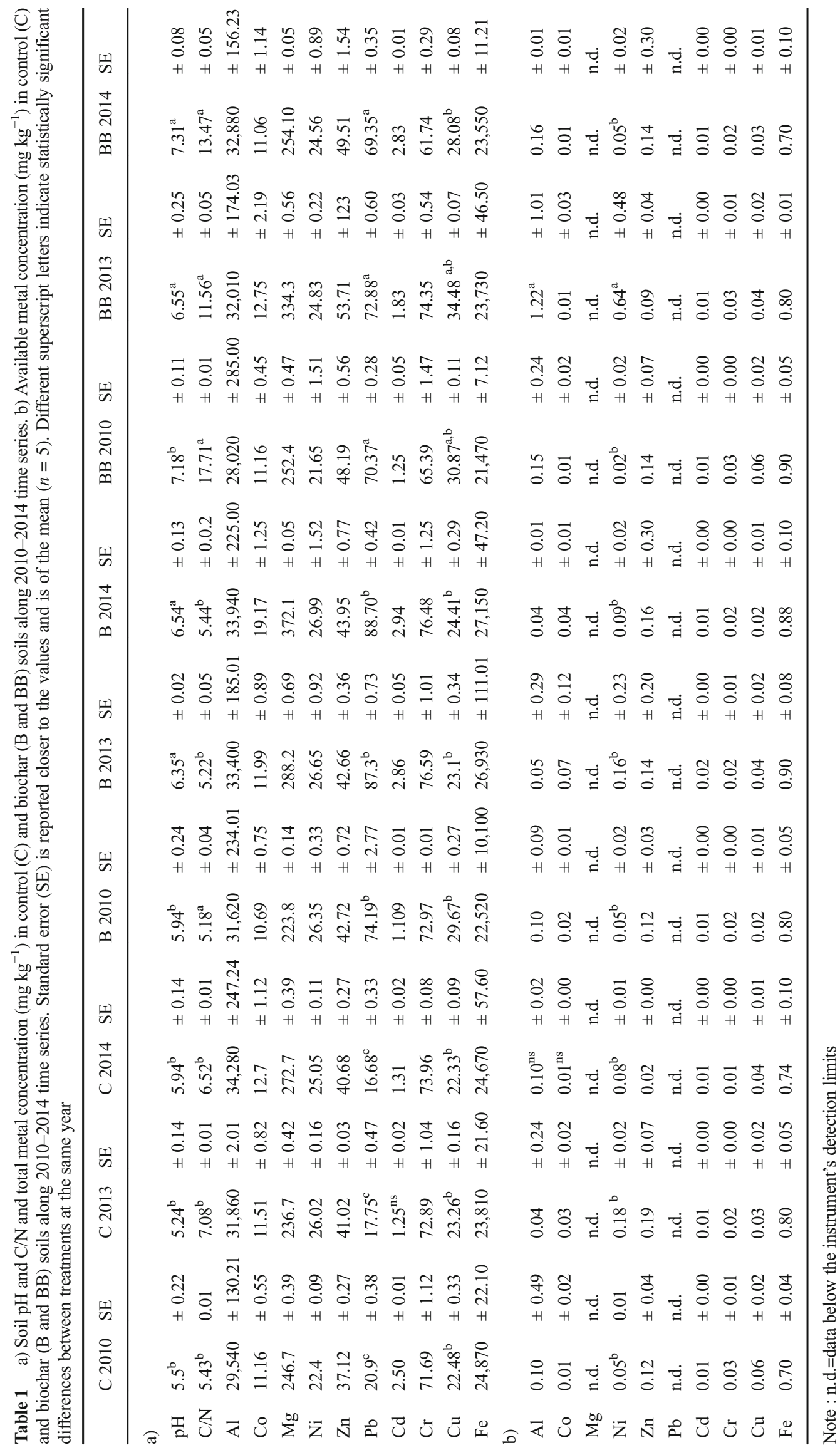


Fig. 2 Soil nutrient content in the control treatment $(\mathrm{C})$ and in the biochar treatments (B and $\mathrm{BB})$ in 2010-2013.Colors indicate different treatments: C (blue), B (red), and BB (green). Bars denote standard error. Different letters above the columns indicate statistically significant differences $(p<0.005)$

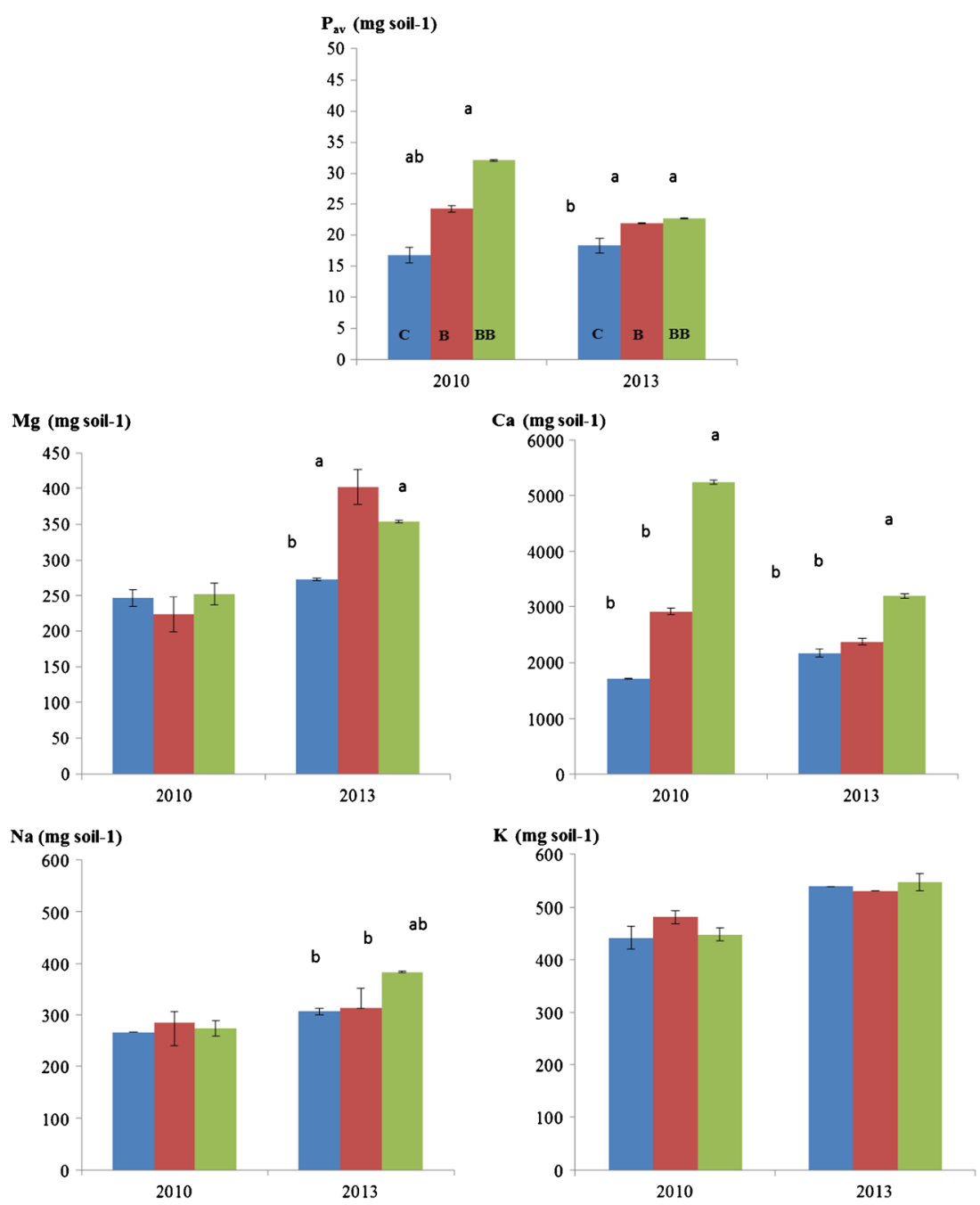

and from $171.9 \pm 37.5$ to $120.3 \pm 13.8 \mathrm{ng} \mathrm{g}^{-1}$, respectively. This was not observed in the control soil samples (varying from $26.9 \pm 10.4$ to $26.8 \pm 4.4 \mathrm{ng} \mathrm{g}^{-1}$ ). All soil samples were dominated by the presence of light molecular weight PAHs, particularly naphthalene (Fig. 3). Phenanthrene and benzo(a)anthracene showed a more evident concentration

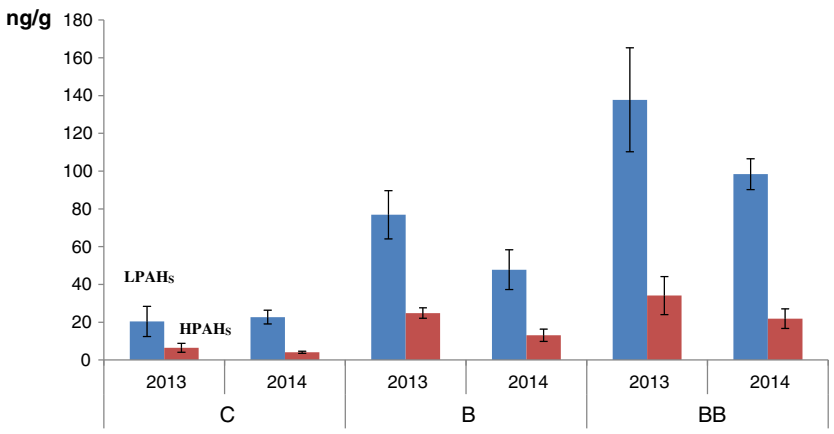

Fig. 3 Low molecular weight (LPAHs) and high molecular weight PAHs (HPAHs) distribution in control (C) and biochar (B and BB) soils. Colors denote the LPAHs (blue) and the HPAHs (red). Whiskers indicate standard errors $(\mathrm{SE})(n=5)$ difference in $\mathrm{B}$ and $\mathrm{BB}$ soils compared to the control and all other PAH congeners.

Biochar application increased the total PAH levels in soil in direct relation with the amount applied. This could be due to the pyrolysis process forming the biochar that leads to the formation of various organic compounds such as dioxins, furans, and PAHs (Oleszczuk et al. 2014). However, even for $\mathrm{BB}$ treatment, the PAH concentrations were much lower (about 102-fold) than the threshold limits for soils according to the Italian environmental legislation (1000 $\mathrm{ng} \mathrm{g}^{-1}$ " $\mathrm{D}$.Lgs $152 / 06$ "). It is known that the concentration and quality of the organic compounds formed in biochar also depend on the initial raw material and temperature of pyrolysis. However, it has been demonstrated that PAH availability in biocharamended soils is lower than that of non-amended soils polluted by PAHs (Rhodes et al. 2010), due to the high affinity of PAHs and other hydrophobic organic compounds with biochar. Furthermore, the $\mathrm{PAH}$ content decreased in the biochar-amended soils in 2014, particularly in the B treatment, although their concentrations were still significantly higher than those of the control soils. This result suggests that long- 
a

Total microbial biomass
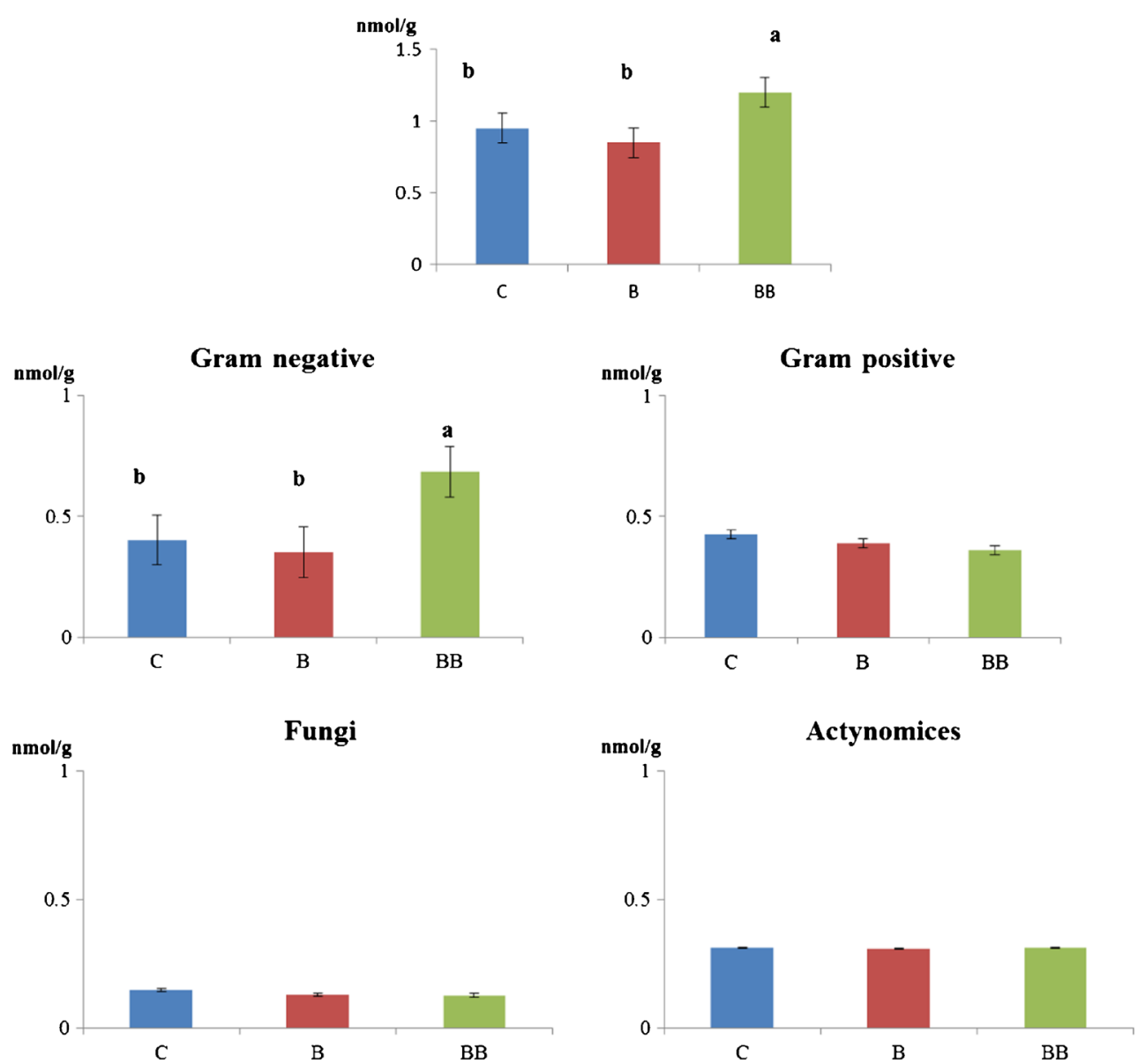

Fig. 4 Sum of the EL-FAME specific microbial groups on 2010 (a) and 2014 (b) for control soil (C), single biochar (B), and double doses of biochar (BB). Different letters denote significant difference between treatments; bars indicate SE with $n=5$

term monitoring is needed to assess the persistence of PAHs in biochar-amended soils. Decrease of PAH concentration in biochar-amended soils could be due to various factors, including leaching, photodegradation, biodegradation, bioaccumulation, and volatilization (Nadarajah et al., 2002), but these factors all act at the same time in field soils. It should also be mentioned that there is a background PAH load on farms that is due to atmospheric deposition from dust produced by burned residues and farm vehicle exhausts (Abdel-Shafy et al. 2016). In our experiments, the presence of a higher percentage of low molecular weight (LPAHs - less than 4 rings) with respect to high molecular weight PAHs (HPAHs - more than 4 rings) could suggest an atmospheric contribution to the PAH level. Moreover, the disappearance of LPAHs from soil was faster with respect to that of HPAHs, as evidenced in both B and $\mathrm{BB}$ experiments, probably related with leaching and/or biodegradation. A few studies have suggested that the presence of some HPAHs could induce some bacterial colonies to biodegrade even recalcitrant molecules such as fluorene and pyrene (Lei et al. 2005). Liao et al. (2016) highlighted that biochar increases the soil biomass (bacteria and fungi) and its activity in the utilization of $\mathrm{C}$ substrate. Together with atmospheric depositions, farm vehicle exhausts influence the background PAH source to soil. The presence of a potential petrogenic source due to the intensive agricultural practices in the investigated area is suggested by the ratio FL/FL + PYR in all samples (B, BB, and control), whose values ranged between 0.3 and 0.6. Moreover, the ratio values of HPAHs/ $\Sigma$ PAHs and LPAHs/HPAHs supported a petrogenic contamination related to diesel emissions of farm vehicles.

The BioTox test, performed for 5 years over the 2010-2014 period, indicated no toxicity for soils treated with $\mathrm{B}$ and $\mathrm{BB}$, except for soil sampled in 2013 where the bioluminescence inhibition reached $20 \%$ in BB treatment. This transient slight toxicity detected for the BB-amended soils could partly be explained by the corresponding transient increase in metal mobility and total PAH level in 2013.

\subsection{Soil microbial community structure}

The EL-FAME profile analysis of soils showed a significant increase $(p<0.01)$ in monounsaturated fatty acids $(16: 1 \mathrm{n} 7 \mathrm{c}$, 
b
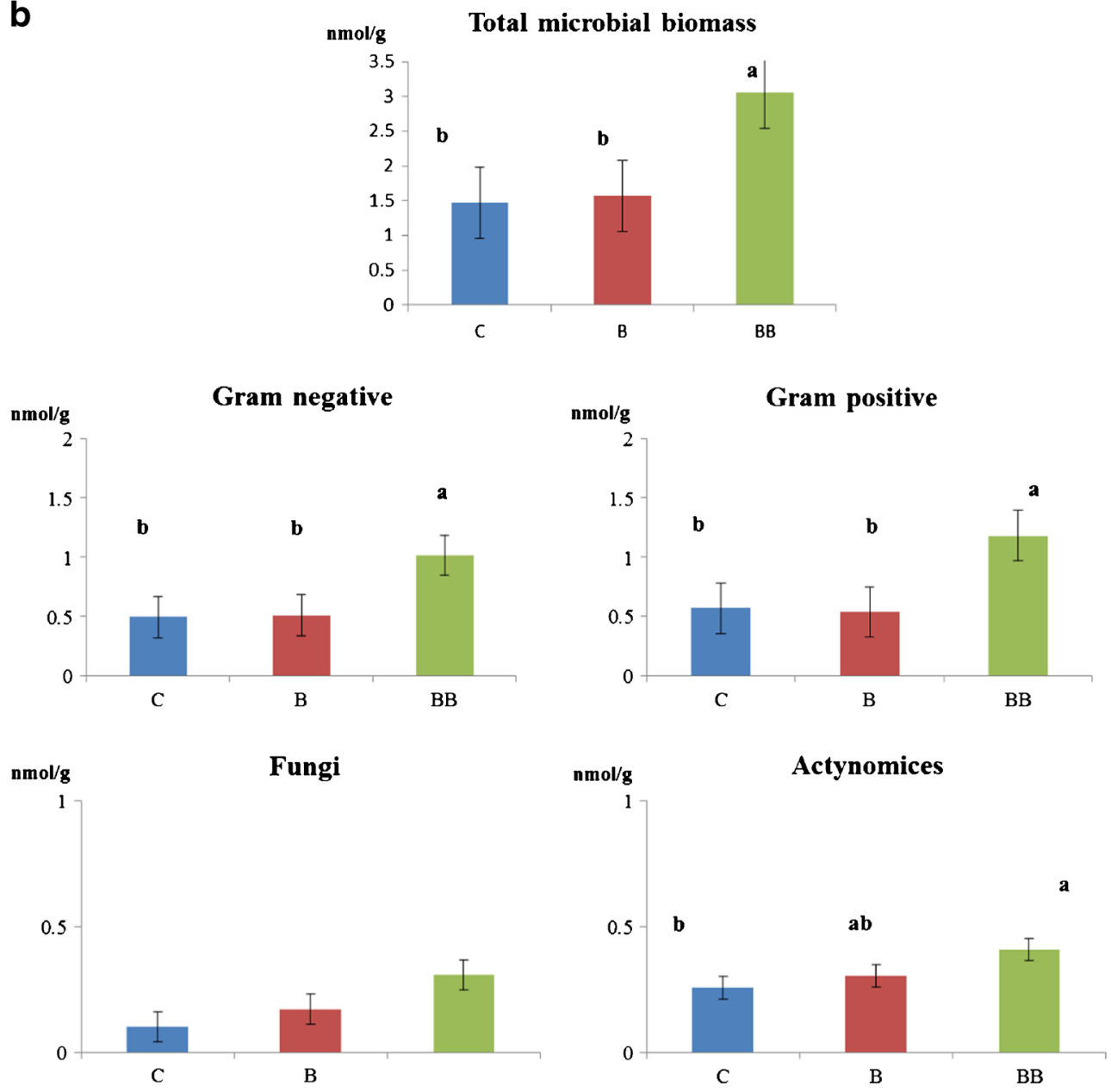

Fig. 4 (continued)

$18: \ln 9 \mathrm{c}, 18: \ln 9 \mathrm{c})$ and in straight-chain saturated fatty acids: 16:0 for BB treatment compared to B and the control (data not shown). Significant increases $(p<0.05)$ over time were observed for 16:1n7c, 18:1n9c, 18:1n9c 16:0 EL-FAMEs and polyunsaturated 18:2w6,9 EL-FAMEs (data not shown). No significant effect was observed in B treatment, compared to the control, except for 18:2w6,9 for soils sampled in 2014. The iso- and anteiso-, i15:0, i16:0, and a15:0 of branched saturated fatty acids significantly increased $(p<0.001)$ in BB 2014 (data not shown).

The sum of the EL-FAME data revealed a significant increase $(p<0.01)$ of soil microbial biomass for BB treatment in both 2010 and 2014 (Fig. 4a, b) whereas the sum of the groupspecific EL-FAMEs indicated an increase of Gram- bacteria only in 2014 (Fig. 4b). The microbial community structure of the soil under B treatment was not significantly different from that of the control soil for any group and year (Fig. 4a, b).

The BB soil showed a persistent change in total EL-FAME content, which can be considered an indication of increased soil microbial biomass (Mummey et al. 2002). Previous studies on soil quality based on the analysis of FAME profiles have shown that abundance of large groups of soil microorganisms is influenced by nutrient concentration and availability (Bailey et al. 2002). The observed increase in total microbial biomass and abundance of fungal bacterial groups in BB soils indicated an overall stimulation of the whole soil microbial community structure. The impact of biochar on soil microbial communities has been reported in short-term laboratory incubation studies (Quilliam et al. 2012), whereas moderate to no impact on soil microbial communities has been reported for biochar amendment of agricultural soils (Imparato et al. 2016; Jenckins et al. 2016). This may be explained by the improvement of soil biophysical conditions conferred by biochar due to its high porosity, which could increase the biological space in soil leading to microbial proliferation (Lehmann and Joseph 2009). Apparently, the potentially larger biological spaces have favored all microbial groups, presumably not altering the decomposition pathways of the studied soils. In addition, since bacterial proliferation also depends on moisture and temperature (Maienza and Bååth, 2014), the increase of total microbial biomass observed in BB treatment could reflect enhanced soil water retention (Baronti et al. 2014) and increased soil thermal capacity (Genesio et al. 2012). 


\section{Conclusion}

The results demonstrate that biochar effects on $\mathrm{pH}$, total PAH levels, and microbial community are dose-dependent. The effect of higher biochar dose does not increase toxic compounds above the limits for soils according to the Italian environmental legislation. The correlation between biochar doses and soil water retention has also been shown. Based on these results and the eco-toxicological test, we conclude that long-term biochar application at both doses in a Mediterranean vineyard has no negative impacts on the soil microbial community. For the first time, we have demonstrated that long-term biochar amendment does not have toxic consequences.

We reinforce the perception that biochar application is a practical and sustainable option for soil amelioration within the context of climate change mitigation. However, long-term experiments to assess the eco-toxicological impacts are advisable in other perennial crops and climate areas.

Acknowledgements We owe special thanks to the Marchesi AntinoriLa Braccesca Estate for their technical support and for hosting the experiment. A special thanks to Luisa Andrenelli and Adriano Baglio (University of Florence, DISPAA) for the support in laboratory analysis. This study was supported by the Italian Biochar Association (ICHAR http://www.ichar.org) and it contributes to the following projects: EuroCHAR project (FP7-ENV-2010 ID-265179) and AgroPyroGas project (Regione Toscana POR CRO FSE 2007-2013 322, asse IV).

\section{References}

Almaroai YA, Usman AR, Ahmad M, Moon DH, Cho JS, Joo YK et al (2014) Effects of biochar, cow bone, and eggshell on $\mathrm{Pb}$ availability to maize in contaminated soil irrigated with saline water. Environ Earth Sci 71(3):1289-1296. https://doi.org/10.1007/s12665-0132533-6

Bailey VL, Smith JL, Bolton H (2002) Fungal-to-bacterial ratios in soils investigated for enhanced C sequestration. Soil Biol Biochem 34: 997-1007. https://doi.org/10.1016/S0038-0717(02)00033-0

Baronti S, Vaccari FP, Miglietta F, Calzolari C, Lugato E, Orlandini S, Pini R, Zulian C, Genesio L (2014) Impact of biochar application on plant water relations in Vitis vinifera (L.) Eur J Agron 53:38-44. https://doi.org/10.1016/j.eja.2013.11.003

Castracani C, Maienza A, Grasso DA, Genesio L, Malcevschi A, Miglietta F, Vaccari FP, Mori A (2015) Biochar-macrofauna interplay: searching for new bioindicators. Sci Tot Environ 536:449456. https://doi.org/10.1016/j.scitotenv.2015.07.019

Genesio L, Miglietta F, Baronti S, Vaccari FP (2015) Biochar increases vineyard productivity without affecting grape quality: results from a four years field experiment in Tuscany. Agric Ecosys Environ 201: 20-25. https://doi.org/10.1016/j.agee.2014.11.021

Genesio L, Miglietta F, Lugato E, Baronti S, Pieri M, Vaccari FP (2012) Surface albedo following biochar application in durum wheat. Environ Res Lett 7:1-8. doi: https://doi.org/10.1088/1748-9326/7/1/014025

Abdel-Shafy HI, Mansour MS (2016) A review on polycyclic aromatic hydrocarbons: source, environmental impact, effect on human health and remediation. Egypt J Pet 25:107-123. https://doi.org/ 10.1016/j.ejpe.2015.03.011

Imparato V, Hansen V, Santos S, Nielsen TK, Giagnoni L, HauggaardNielsen H, Johansen A, Renella G, Winding A (2016) Gasification biochar has limited effects on functional and structural diversity of soil microbial communities in a temperate agroecosystem. Soil Biol Biochem 99:128-136. https://doi.org/10.1016/j.soilbio.2016.05.004

Jenkins JR, Viger M, Arnold EC, Harris ZM, Ventura M, Miglietta et al (2016) Biochar alters the soil microbiome and soil function: results of next-generation amplicon sequencing across Europe. GCB Bioenergy 9:591-612. https://doi.org/10.1111/gcbb.12371

Lakanen E, Erviö R (1971) A comparison of eight extractants for the determination of plant available micronutrients in soils: jubilee issue in honour of professor Erkki Kivinen Rector of Helsinki University 123:223-232. http://jukuri.mtt.fi/handle/10024/472471

Lappalainen J, Juvonen R, Nurmi J, Karp M (2001) Automated color correction method for Vibrio fischeri toxicity test. Comparison of standard and kinetic assays. Chemosphere 45:635-641. https://doi. org/10.1016/S0045-6535(00)00579-8

Lehmann J, Joseph S (2009) Biochar for environmental management: an introduction. In: Lehmann J, Joseph S (eds) Biochar for environmental management: science and technology. Earthscan Publ., London, UK, pp 1-12 ISBN 978-1-84407-658-1

Lei L, Khodadoust AP, Suidana MT, Tabak HH (2005) Biodegradation of sediment bound PAHs in field-contaminated sediment. Water Res 39:349-361. https://doi.org/10.1016/j.watres.2004.09.021

Liao N, Li Q, Zhang W, Zhou G, Ma L, Min W et al (2016) Effects of biochar on soil microbial community composition and activity in drip-irrigated desert soil. Eur J Soil Biol 72:27-34. https://doi.org/ 10.1016/j.ejsobi.2015.12.008

Mackie KA, Marhan S, Ditterich F, Schmidt HP, Kandeler E (2015) The effects of biochar and compost amendments on copper immobilization and soil microorganisms in a temperate vineyard. Agric Ecosys Environ 201:58-69. https://doi.org/10.1016/j.agee.2014.12.001

Maienza A, Bååth E (2014) Temperature effects on recovery time of bacterial growth after rewetting dry soil. Microb Ecol 68:818-821. https://doi.org/10.1007/s00248-014-0446-x

Mattei P, Cincinelli A, Martellini T, Natalini R, Pascale E, Renella G (2016) Reclamation of river dredged sediments polluted by PAHs by co-composting with green waste. Sci Tot Environ 1(566-567): 567-574. https://doi.org/10.1016/j.scitotenv.2016.05.140

Mummey DL, Stahl PD, Buyer JS (2002) Microbial biomarkers as an indicator of ecosystem recovery following surface mine reclamation. Applied Soil Ecol 21:251-259. https://doi.org/10.1016/ S0929-1393(02)00090-2

Nadarajah NV, Van Hamme J, Pannu J, Singh A, Ward O (2002) Enhanced transformation of polycyclic aromatic hydrocarbons using a combined Fenton's reagent, microbial treatment and surfactants. App Microb Biotech 59:540-544. https://doi.org/10.1007/ s00253-002-1073-x

Nannipieri P, Giagnoni L, Renella G, Puglisi E, Ceccanti B, Masciandaro G, Fornasier F, Moscatelli MC, Marinari S (2012) Soil enzymology: classical and molecular approaches. Bio Fert Soils 48:743-762. https://doi.org/10.1007/s00374-012-0723-0

Oleszczuk P, Jośko I, Kuśmierz M, Futa B, Wielgosz E, Ligęza S, Pranagal J (2014) Microbiological, biochemical and ecotoxicological evaluation of soils in the area of biochar production in relation to polycyclic aromatic hydrocarbon content. Geoderma 213:502-511. https://doi.org/10.1016/j.geoderma.2013.08.027

Olsen SR, Sommers LE (1982) Determination of available phosphorus. In: Page AL, Miller RH, and Keeney DR (eds) Method of Soil Analysis, vol 2. American Society of Agronomy, Madison, WI, p. 403

Quilliam RS, Marsden KA, Gertler C, Rousk J, DeLuca TH, Jones DL (2012) Nutrient dynamics, microbial growth and weed emergence in biochar amended soil are influenced by time since application and reapplication rate. Agric Ecosyst Environ 158:192-199. https://doi. org/10.1016/j.agee.2012.06.011

Rhodes AH, McAllister LE, Chen R, Semple KT (2010) Impact of activated charcoal on the mineralization of 14C-phenanthrene in soils. 
Chemosphere 79:463-469. https://doi.org/10.1016/j.chemosphere. 2010.01.032

Rombolà AG, Meredith W, Snape CE, Baronti S, Genesio L, Vaccari FP, Fabbri D (2015) Fate of soil organic carbon and polycyclic aromatic hydrocarbons in a vineyard soil treated with biochar. Environ Sci Technol 49:11037-11044. https://doi.org/10.1021/acs.est.5b02562

Schmidt HP, Kamman C, Niggli C, Evangelou MWH, Mackie KA, Abiven S (2014) Biochar and biochar-compost as soil amendments to a vineyard soil: influences on plant growth, nutrient uptake, plant health and grape quality. Agric Ecosys Environ 191:117-123. https://doi.org/10.1016/j.agee.2015.07.027

Schutter ME, Dick RP (2000) Comparison of fatty acid methyl ester (FAME) methods for characterizing microbial communities. Soil Sci Soc Am J 64:1659-1668 10(12):e0145501
Stefaniuk M, Oleszczuk P, Bartmiński P (2016) Chemical and ecotoxicological evaluation of biochar produced from residues of biogas production. J Hazard Mater 318:417-424. https://doi.org/10.1016/j. jhazmat.2016.06.013

Yang Y, Ma S, Zhao Y, Jing M, Xu Y, Chen J (2015) A field experiment on enhancement of crop yield by rice straw and corn stalk-derived biochar in Northern China. Sustainability 7:13713-13725. https:// doi.org/10.3390/su71013713

Zelles L (1999) Fatty acid patterns of phospholipids and lipopolysaccharides in the characterization of microbial communities in soil: a review. Biol Fertil Soils 29:111-129. https://doi.org/10.1007/ s003740050533 